\title{
Lieber Herr Professor Kemper,
}

ein Glückwunsch zu so einem hohen und stolzen Jubiläum und Anlass sollte sicherlich das Lebenswerk würdigen. Dies an dieser Stelle angemessen zu tun, erscheint uns kaum möglich angesichts der zahllosen Funktionen, Auszeichnungen, Leistungen und Aktivitäten, die Sie in Ihrem langjährigen Wirken und Ihrem unglaublichen beruflichen Engagement hatten und erhalten haben. Es würde den Rahmen an dieser Stelle sehr deutlich überschreiten - diese Tatsache spricht bereits für Sie und Ihr großes Lebenswerk. Wir möchten uns an dieser Stelle daher beschränken auf das, was Sie mit der ESCOP verbindet und verbunden hat.

Maßgeblich durch Ihre breit aufgestellte Initiative, die Akzeptanz der Phytotherapie in Europa zu stärken und auszubauen, hatten Sie 1989 im kleinen Kreis die Gründung der ESCOP initiiert. Sie taten dies unter dem Einfluss verstärkter politischer Diskussionen und der Idee einer in Europa harmonisierten Bewertung pflanzlicher Arzneimittel. Dieser Vorstoß mündete in eine Pionierarbeit der Erstellung der ersten europäischen Monografien zur medizinischen Verwendung sowie der Wirksamkeit und Unbedenklichkeit von Arzneipflanzen, einem Modell, das später von der europäischen Gesetzgebung zu pflanzlichen Arzneimitteln aufgegriffen wurde. Damit etablierte sich auch deren regulatorische Harmonisierung auf europäischer Ebene - so wie dies in dieser Ausgabe der ZPT aus verschiedenen Blickwinkeln betrachtet und dargestellt wird.

Sie, lieber Herr Professor Kemper, standen der ESCOP als deren Präsident über viele Jahre bis 2010 vor und haben sich auf vielen wissenschaftlichen, pharmapolitischen und politischen Ebenen höchst intensiv und sehr persönlich engagiert. Zudem - und das sei Ihrem Charisma zuerkannt - haben Sie viele
Kollegen und Mitstreiter bewegen und mitreißen können, den europäischen Gedanken in Ihrem Sinne und in der Sache zum Wohle der Phytotherapie weiter voranzubringen.

Wir, als Vertreter der ESCOP, bedanken uns herzlichst für Ihr langjähriges Engagement - und seien Sie sicher - Sie haben uns und viele andere motiviert, es Ihnen gleich zu tun und sich für die medizinisch-wissenschaftlich berechtigten Belange der Phytotherapie und die Phytopharmaka einzusetzen. Dafür möchten wir Ihnen als einem der wichtigsten Vorreiter an dieser Stelle danken!

Wir wünschen Ihnen alles Gute zu Ihrem 90. Geburtstag.

Dr. Tankred Wegener, Präsident der ESCOP

Dr. Barbara Steinhoff, Vorsitzende des Scientific Committee

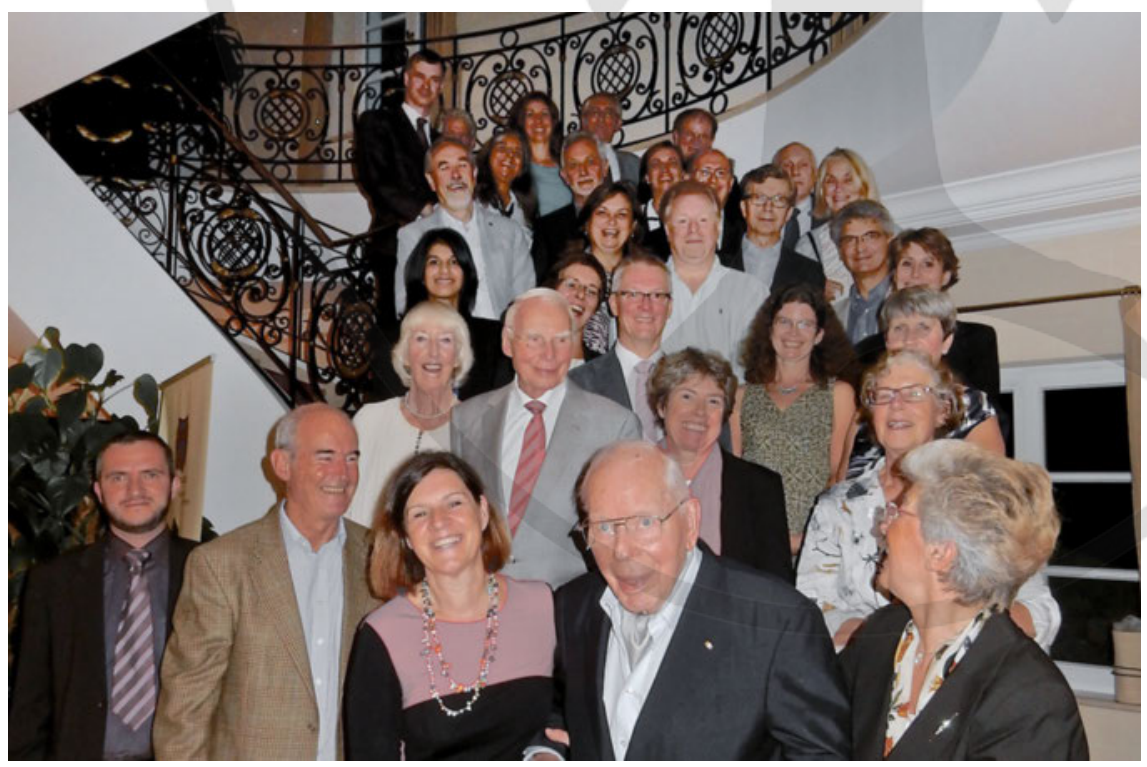

Professor Kemper und die ESCOP-Aktiven anlässlich des 25-jährigen ESCOP-jubiläums 2014. @ Simon Mills 